\title{
Association between Discomfort and Fatigue around Neck Area due to Portable Electronic Devices in College Students
}

\author{
Bhavna Anand, Shreya Thakur and Priya Sharma
}

\begin{abstract}
Aim: To determine the correlation between portable electronic devices (smartphone, laptop and tablet) usage and pain, neck disability, fatigue among collegiate population. Method: one hundred $(\mathrm{N}=100)$ students as subjects within age group of 18 to 26 years both males and females from amity institute of physiotherapy were participated. Students who were using portable electronic devices (smartphones, laptop and tablets) for more than 5 hours or more per day were included in the study. Students who were having any chronic medical illness and musculoskeletal disease or anomalies such as muscle strain, muscle sprain, any neck deformity (torticollis, cervical rib) and surgery were excluded. Numeric pain rating scale, neck disability index questionnaire and fatigue impact scale were used for assessment. Results: It was found that there was partially negative correlation between the numbers of hours of portable electronic device usage and fatigue impact that is $(r=-0.02)$. Similarly, a partially negative correlation was noted between the number of hours of portable electronic device usage and neck pain i.e. $(\mathrm{r}=-0.093)$. Astonishingly a partially positive correlation was found between the number of hours of portable electronic device usage and neck disability $(r=0.05)$. Conclusion: longer hours of usage of portable electronic devices may not cause pain, neck disability and the impact of fatigue may be less when proper rest and recovery time is given to the subjects in between and after the working hours.
\end{abstract}

\section{Bhavna Anand}

Teaching Associate

Amity Institute of Physiotherapy

Amity University, Noida, (Uttar Pradesh) India

E-mail: banand@amity.edu

Shreya Thakur

B.P.T. Intern

Amity Institute of Physiotherapy

Amity University, Noida, (Uttar Pradesh) India

E-mail: imshreyathakur@gmail.com

Priya Sharma

B.P.T. Intern

Amity Institute of Physiotherapy

Amity University, Noida, (Uttar Pradesh) India

E-mail: priyasharma782@yahoo.com
Key Words: Portable Electronic Devices (PED), Neck disability, Neck pain, SmartPhone (SP), Laptop (LP), Tablet (TB)

DOI: $10.18376 / j e s p / 2020 / v 16 / i 2 / 157453$

\section{Introduction}

The digital revolution has sincerely influenced everyday living, evident in the ubiquity of mobile devices and the coherent integration of technology into common tasks such as shopping, reading, and finding directions (Abigail and Kari 2014). The utilization of computers, mobile devices, and the Internet is at the top level to date and is anticipated to continue to increase as the technology is becoming more accessible, especially for users in developing countries (Allan 2009). The utilization of new technology for a prolonged time is having a profound impact on general body posture. The utilization of computers is related with neck and wrist pain symptoms, however there 


\section{Journal of Exercise Science \& Physiotherapy Vol.16 No.2 (July to December) 2020 ISSN: 0973-2020 (Print) $\mathrm{I}_{2} \mathrm{OR}$ Impact Factor $=6.850 \quad$ ISSN: 2454-6089 (Online)}

is less research data analyzing the use of tablets, computers, which are being used with unequivocal frequency. Neck pain is a global health issue as it heavily contributes to global disability and reduces work productivity. Computer used with poor posture and bad sitting arrangements leads to neck, shoulder and back pain with long term ill effects. The anatomy of the neck or cervical spine is complex. It has a coordinated network of the muscles, bones, nerves, and spinal cord. After pain, depression and arthralgia neck pain is the fourth leading cause of disability globally (Abdullah et al., 2018). Approximately half of the population experience clinical neck pain once in their lifetime. (André 2008). Tablet and computers which are not easily adjustable to daily work and needs may enhance poor posture (Lepp et al., 2015). No ample research was done on posture related to tablet and computers extensive use. As compared to laptop computer use tablet uses likely results in different postural changes. Using tablet for day to day work causes postural changes such as excessive neck flexion, ulnar deviation and excessive wrist flexion (Lepp et al., 2015). A study reported that, $82 \%$ of college students owned a laptop and it was their only computer. Further, it was found that, on average, students used their computers for $21.3 \mathrm{~h}$ a week (Fadi et al., 2019).

\section{Materials and Method}

Study design was cross-sectional study design. One hundred $(\mathrm{N}=100)$ subjects within the age group of 18-26 years both male and female from Amity Institute of Physiotherapy were participated in the study. The inclusion criteria of the study were that the students should have their own PED`s, only students should participate regardless of their handedness and gender, students who use portable electronic devices for $5 \mathrm{hrs}$ or more per day. The exclusion criteria were that the students having any chronic medical illness, Musculoskeletal disease or anomalies, Muscle strain, Muscle sprain, Any neck deformity torticollis, cervical rib, etc. and those who had previous surgeries in the neck or shoulder and any recent injury of the neck.

Independent variables are number of hours of PED`s usage i.e. $\mathrm{SP}+\mathrm{LP}+\mathrm{TB}+(\mathrm{SP}+\mathrm{LP})+(\mathrm{SP}+\mathrm{TB})$ and dependent variables are NPRS , FIS and NDI. (NPRS - Numeric pain rating scale; NDIS - Neck disability index scale; FIS - Fatigue Impact Scale)(SP - smart phone; LP - Laptop; TB - Tablet) Informed consent was taken from the students. The data was collected through the survey method. The forms were distributed to the students. The data collected was listed in the form of a master chart in Microsoft Excel sheet and further data calculation was also done in the same application. The mean and standard deviations were calculated for all the characters taken in the study (for example - age, weight, height, BMI, etc). A total of 120 students completed the survey and 100 were selected for the study. The data analysis was done using SPSS software. The data analysis was done at a p-value of 0.05 which was adopted as a threshold for significance. Pearson's correlation test was utilized to find out the correlation. Out of these 100 students 87 were females and 13 were males. The mean of all the characteristics (height, weight, BMI) were observed.

\section{Results}

Table 1 show the mean and standard deviation of eight components used in the study such as age, height, weight, BMI, NPRS, NDIS, FIS, and PEDU (in hours). The mean age, height, weight and BMI, of participants was $21.5 \pm 1.37$ year, $163.61 \pm 9.54 \mathrm{~cm}, 58.5 \pm 10.2 \mathrm{~kg}$ and $21.8 \pm 3.27$ respectively. 
Journal of Exercise Science \& Physiotherapy Vol.16 No.2 (July to December) 2020

ISSN: 0973-2020 (Print) $\quad I_{2}$ OR Impact Factor $=6.850 \quad$ ISSN: 2454-6089 (Online)

Table 1. Mean and Standard deviation of all characters

\begin{tabular}{|l|c|}
\hline Parameters & Mean \pm St. Deviation \\
\hline Age & $21.51 \pm 1.37$ \\
\hline Height & $163.61 \pm 9.54$ \\
\hline Weight & $58.5 \pm 10.2$ \\
\hline BMI & $21.8 \pm 3.27$ \\
\hline NPRS & $2.91 \pm 2.08$ \\
\hline NDI & $7.86 \pm 7.35$ \\
\hline FIS & $39.307 \pm 27.56$ \\
\hline $\begin{array}{l}\text { PED USAGE ( in hours) } \\
\text { SP+LP+TB+(SP+LP)+(SP+TB) }\end{array}$ & $10.97 \pm 6.647$ \\
\hline
\end{tabular}

(BMI - Body Mass Index; NPRS - Numeric pain rating scale; NDIS - Neck disability index scale; FIS - Fatigue Impact Scale)

On analysis it was found that Physiotherapy students use PED`s for an average of $8.24 \pm 4.06$ hours per day.

Table 2 . Pearson's Correlation between Independent and Dependent Variables

\begin{tabular}{|l|c|c|c|}
\hline $\begin{array}{l}\text { Dependent Variable } \rightarrow \\
\text { Independent } \\
\text { Variable } \downarrow\end{array}$ & NPRS & NDI & FIS \\
\hline $\begin{array}{l}\text { Number of hours of PED`s } \\
(\mathrm{sp}+\mathrm{lp}+\mathrm{tb}+(\mathrm{sp}+\mathrm{lp})+(\mathrm{sp}+\mathrm{tb}))\end{array}$ & $\begin{array}{c}-0.0499 \\
\text { Insignificant }\end{array}$ & $\begin{array}{c}0.0019 \\
\text { Insignificant }\end{array}$ & $\begin{array}{c}-0.1237 \\
\text { Insignificant }\end{array}$ \\
\hline
\end{tabular}




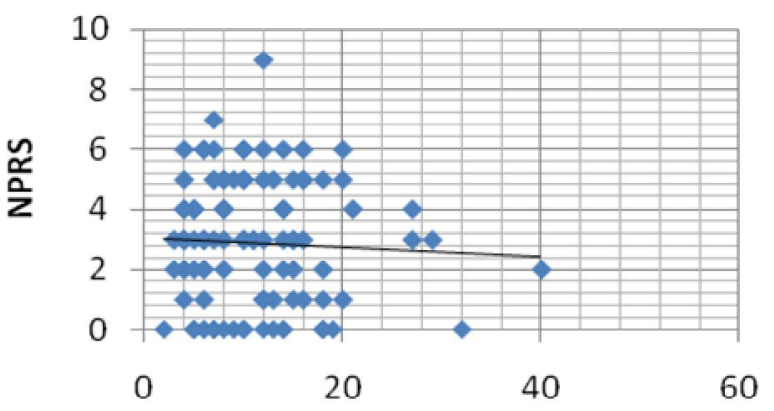

- Series 1

L Linear (Series1)

\section{PRTABLE ELECTRONIC DEVICES USE DURATION (HOURS)}

Figure 1. Correlation between duration of portable electronic devices use and pain

Figure 1 show a moderately negative correlation between duration of portable electronic devices use (in hours) and pain (SP - smart phone; LP - Laptop; TB - Tablet). Figure 1 shows that with an increase in the number of hours of PEDU there is a decrease in pain. The value of $r=-0.0499$ has a week magnitude/ less value but the direction is negative which depicts a moderately negative correlation of very little magnitude (Table 2).

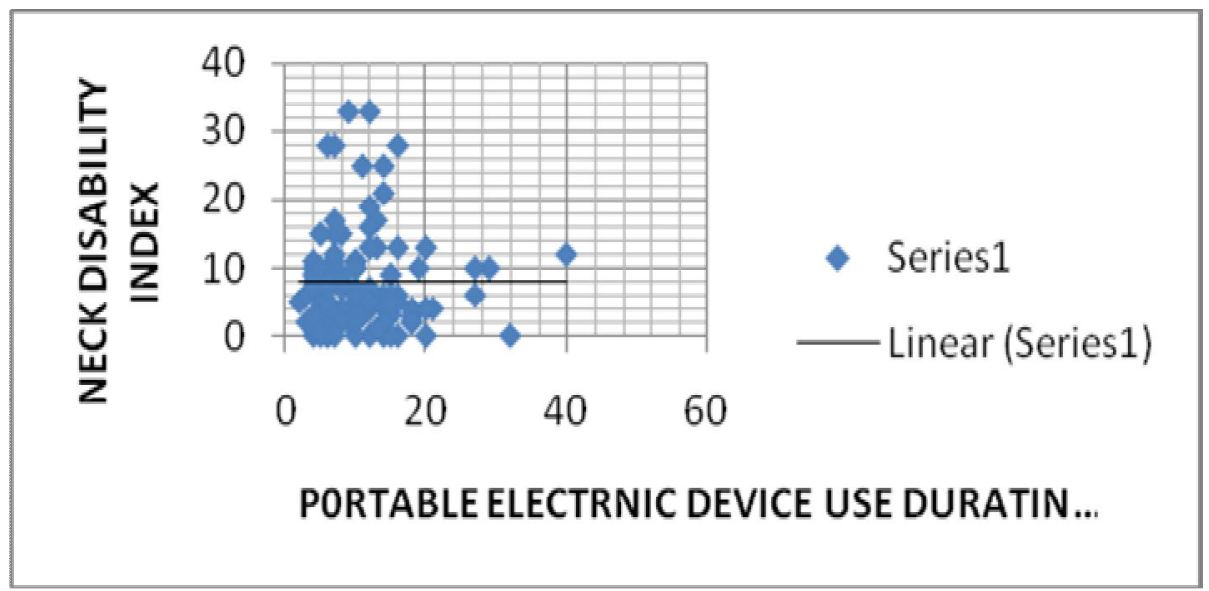

Figure 2. Correlation between duration of portable electronic device use and neck disability

Figure 2 shows that with an increase in hours of PEDU, there is an increase in neck disability. The value of $r=0.0019$ which is again very less in magnitude but has a positive direction which depicts a moderately positive correlation (Table 2 ). 


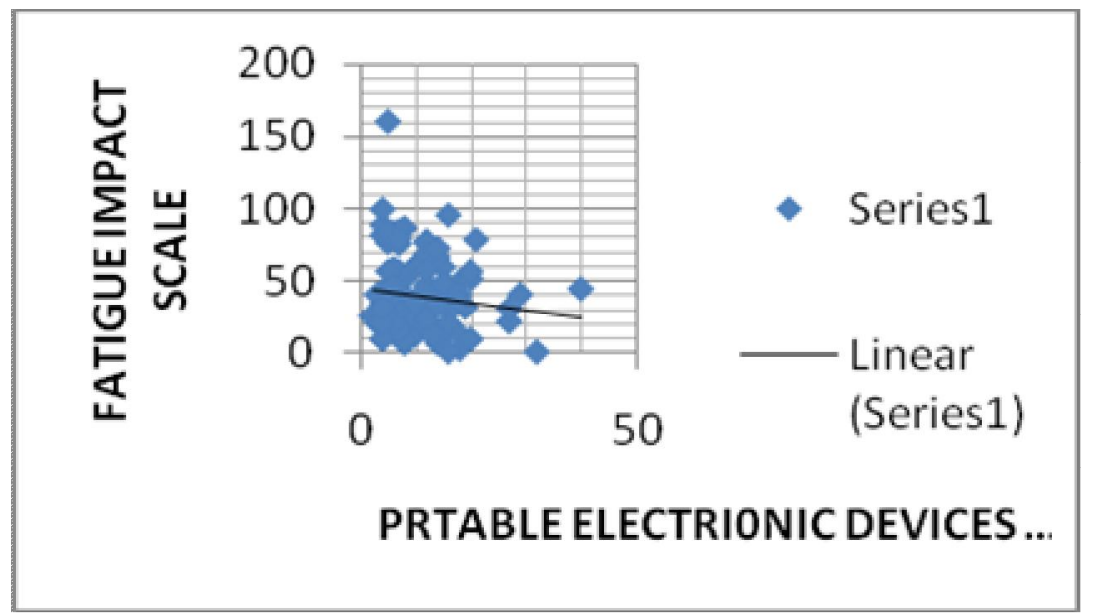

\section{Figure 3. Correlation between the duration of portable electronic devices use and the impact of fatigue}

Figure 3 shows that with an increase in the number of hours of PEDU there is a reduction in the impact of fatigue. The value of $r=-0.1237$ has less magnitude but in a negative direction, this depicts that there is a moderately negative correlation of less magnitude (Table 2).

\section{Discussion}

To the best of our knowledge, this is an exclusive study to use fatigue impact scale to measure the impact of fatigue and limitation on daily activity among the students of Amity University, Noida, Uttar Pradesh, India. The students were informed about the consent form and everything was explained to them. A total of 120 students filled the form and 100 were selected for the study on the basis of inclusive and exclusion criteria. In this study, a noteworthy negative correlation $(\mathrm{r}=-0.09)$ was found between the duration of the use of portable electronic device and neck pain (Abdullah et al., 2018).Besides, the literature showed that the prevalence of neck pain increases with age (Abdullah et al., 2018). In this context, the mean age of students in this study (21.54 \pm 1.38$)$ might be a contributing factor for the above-stated result of the correlation between pain and portable electronic device usage duration (Andre et al., 2008). According to a study done by Andre et al.,(2008) a multitude of possible influencing factors investigated in the above-stated study was as follows: There has been only more than 20 years on the job, when there is high lack of job satisfaction; when the person is doing typing for a minimum of 6 hours every day ; when there is limitations to take breaks in between continuous working hours; This significantly increased the 12month prevalence of one or more musculoskeletal symptoms. (Andre et al., 2008).But the present study was done on students and all influencing factors investigated above are being contradicted as first the students used these devices for playing games, projects, for leisure activities but not for the job. The mean duration of smartphone use, laptop use, tablet use in years is given below in the Table 3. 


\section{Journal of Exercise Science \& Physiotherapy Vol.16 No.2 (July to December) 2020 ISSN: 0973-2020 (Print) $\quad \mathrm{I}_{2}$ OR Impact Factor $=6.850 \quad$ ISSN: 2454-6089 (Online)}

\section{Table 3. Mean of years of PED usage for smartphones, laptops, and tablets}

\begin{tabular}{|l|l|l|}
\hline $\begin{array}{l}\text { Smartphone use in a number of } \\
\text { years }\end{array}$ & $\begin{array}{l}\text { Laptop use in a number of } \\
\text { years }\end{array}$ & $\begin{array}{l}\text { Tablet use in a number of } \\
\text { years }\end{array}$ \\
\hline $5.39 \pm 2.1$ & $3.24 \pm 3.08$ & $0.4 \pm 1.33$ \\
\hline
\end{tabular}

Second, the students use these devices according to their satisfaction or needs (Abdullah et al., 2018). Third students usually use these devices for less of typing work and that too occasionally for projects, presentations, etc., even then they do not use it continuously for 6 hours straight per day and there is no limitation on the number of breaks and duration of brakes on them. Another reason for negative correlation may be the participants of the current research study indicated fewer symptoms as they might be thinking mainly of work-related symptoms which shows negative reporting bias (Abdullah et al., 2018). A moderately positive correlation of $r=0.05$ is seen in this study between the number of hours of portable electronic device used and neck disability among the student population. Smartphones have replaced laptops and tablets in our daily life. We used them frequently for different communication and reading purposes it causes flexion in the neck that causes stress in the neck. The contagious forward bending poses risk for early arthritis and change in neck alignment and may result in permanent damage (Cohen et al., 2015). The moderately positive correlation shows that with an increase in hours usage of portable electronic devices using the neck disability increases (Cohen et al., 2015). The direction of correlation is positive, but the magnitude is weak $=0.05$. There is a moderately negative correlation between the number of hours of portable electronic device usage and fatigue. The direction of correlation is negative, but the magnitude is 0.02 which is very week. According to a study done by Kim et $\mathrm{Al}$, looking downwards increases muscle fatigue more easily than does looking upwards (Exelmans et al., 2016). This implies that posture is a very important factor in context to fatigue but in our study, the relationship only between the number of hours of portable electronic devices used and fatigue has been calculated and posture has not been considered (Brau et al., 2020).

\section{Conclusion}

This study shows that there is no significant correlation between the number of hours of portable electronic device usage and neck pain, fatigue, however, it may influence neck disability but here the result was insignificant at $p=0.5$.The results of the study nullify the claim that the experimental result is different from or better than the observed already that is the null hypothesis is accepted. This also shows that: longer hours of usage of portable electronic devices may not cause pain, neck disability and the impact of fatigue maybe less when proper rest and recovery time is given to the subjects in between and after the working hours.

\section{Acknowledgment}

The authors are thankful to the head of the department of Amity Institute of Physiotherapy for their support.

\section{Reference(s)}

Abdullah Farooq Khan, Syed Faraz Ul Hassan Shah Gillani and Wahid A.2018. Are you suffering pain neck due to smartphone text neck syndrome. Pakistan Journal of Medical and Health Sciences 12(3):1095-1097

Abigail Werth.and Kari Babski-Reeves.2014.Effects of portable computing devices on posture, muscle activation levels, and efficiency. Applied Ergonomics, 45(6):1603-9.

Allan 1.basbaum.et Al. 2009.Cellular and molecular mechanisms of pain, NIH public Access cell author manuscript,2009.

Andre Klussmann et al.; Musculoskeletal symptoms of the upper extremities and neck: A cross-sectional study on prevalence and symptom- predicting factors at visual display terminal (VDT) workstations; $B M C$ Musculoskeletal Disorders 9, Article number 96 (2008). 


\section{Journal of Exercise Science \& Physiotherapy Vol.16 No.2 (July to December) 2020 \\ ISSN: 0973-2020 (Print) I IOR Impact Factor $=6.850 \quad$ ISSN: 2454-6089 (Online)}

Brau Mar Sánchez, Begoña Domenech-Amigot, Francisco Brocal-Fernández, Jose Antonio QuesadaRico, Mar Seguí-Crespo.2020. Prevalence of Computer Vision Syndrome and Its Relationship with Ergonomic and Individual Factors in Presbyopic VDT Workers Using Progressive Addition Lenses. Int J Environ Res Public Health 2020 Feb 5;17(3):1003. doi: 10.3390/ijerph17031003.

Cohen, Steve P. et al.2015. Epidemiology, diagnosis and treatment of neck pain; Mayo Foundation for Medical Education and Research, Mayo Clin Proc 90(2):284-99. doi: 10.1016/j.mayocp.2014.09.008.

Exelmans Liese and Jan Van den Bulck.2016.Bedtime mobile phone use and sleep in adults. Soc Sci Med 2016 Jan;148:93-101. doi: 10.1016/j.socscimed.2015.11.037. Epub 2015 Dec 2.

Fadi Al-Hadidi , Isam Bsisu , Saif Aldeen AlRyalat, Belal Al-Zu'bi, Rasha Bsisu, Mohammad Hamdan, Tareq Kanaan, Mohamad Yasin, Omar Samara. association between mobile phone use and neck pain in university students: a cross-sectional study using a numeric pain rating scale for evaluation of neck pain, PLOS ONE online journal, 2019. https://doi.org/10.1371/journal.pone.0217231

Lepp Andrew, Jacob E. Barkley, Aryn C. Karpinski.2015. The Relationship between Cell Phone Use and Academic Performance in a Sample of U.S. College Students. SAGE Open online Volume 5; Issue:1

Conflict of Interest: None declared 